Journal of Nepal Geological Society, 2019, vol. 58 (Sp. Issue), pp. 163-172

DOI: https://doi.org/10.3126/jngs.v58i0.24601

\title{
Landslide susceptibility mapping using Weight of Evidence Method in Haku, Rasuwa District, Nepal
}

\author{
*Arishma Gadtaula and Subodh Dhakal \\ Department of Geology, Tri-Chandra Campus, Tribhuvan University, Kathmandu, Nepal \\ *Corresponding author: arish123gadtaula@gmail.com
}

\begin{abstract}
The 2015 Gorkha Earthquake resulted in many other secondary hazards affecting the livelihoods of local people residing in mountainous area. Plenty of earthquake induced landslides and mass movement activities were observed after earthquake. Haku region of Rasuwa was also one of the severely affected areas by co-seismic landslides triggered by the disastrous earthquake. Statistics shows that around 400 families were relocated from Haku Post-earthquake (MoFA, 2015). A total of 101 co-seismic landslides were focused during the study and were verified during the fieldwork in Haku village. The conditioning factors used in this study were slope, aspect, elevation, curvature (plan and profile), landuse, geology and PGA. The conditioning factor maps were prepared in GIS working environment and further analysis was conducted with the assistance of Google earth. This study used Weight of Evidence (WoE), a bivariate statistical model and its performance was assessed. The susceptibility map was further characterized into five different classes namely very low, low, high, medium and very high susceptibility zones. The statistical analysis obtained from the results of the susceptibility map prepared by using WoE model gave the results that maximum area percentage of landslide distribution was observed in medium and high susceptibility classes i.e. $38 \%$ and $33 \%$ followed by very high (13\%), low (10\%) and very low classes (5.8\%) About $25 \%$ of the total landslides are separated to validate the prepared model used in the landslide susceptibility zonation. The overlay method predicts the reliability of the model.
\end{abstract}

Keywords: Gorkha Earthquake, Earthquake induced landslides, Weight of Evidence, Susceptibility, PGA

Paper Received: 30 Dec 2018

Paper Accepted: 27 Mar 2019

\section{INTRODUCTION}

The active tectonic setting of the Nepal Himalaya makes it one of the most earthquake susceptible countries in the globe (Dewey and Burke, 1973). In addition, diverse geological structures, fragile topography, high precipitation, deeply weathered rock material and active tectonics altogether with the socio-economic instability makes Nepal vulnerable to several natural disasters. Landslides are one of the major natural disasters in Nepal which leads to huge social and economic losses. Landslides can occur under several climatic, topographic and geological conditions. In Nepal, more than $80 \%$ land is covered by mountainous area and that are prone to landslide which have led to monetary losses of billions in last few decades (Amatya, 2016). Landslides can be triggered by various external factors such as incessant rainfall, earthquakes, extreme precipitation or rapid stream erosion.

A catastrophic earthquake with moment magnitude of 7.8 shook Nepal at local time 11:56 on 25th of April 2015. The statistics by the Ministry of Home Affair (MoHA, 2015) gives the information that as a result of the earthquake 8962 people were killed and thousands of people became homeless. Rasuwa is one of the worst affected districts by the 25th April earthquake. Approximately, 430 people have been reported killed and 753 injured (MoFA, 2015) after the 2015 Gorkha Earthquake. Large co-seismic landslides were triggered along Haku VDC of Rasuwa posing serious issues to the settlement. Approximately 400 families were displaced from Haku and relocated after the earthquake disaster (MoFA, 2015). According to Keefer (1994), earthquakes can trigger different types of secondary natural hazards; among them landslides are the most common. Earthquake induced landslides have garnered the interest and attention among the researchers as the shaking generated due to the earthquake may weaken the slope which may fail the hillslope when triggered by rainfall or a new earthquake.

The topography of this area is highly dissected and rough, with high north-east relief which made it susceptible for such earthquake induced landslides. Approximately 400 families were displaced from Haku and relocated after the earthquake disaster (MoFA, 2015). Absence of proper roadways hindered the identification of earthquake induced landslides in Haku, Rasuwa district Post-Earthquake. The topography of this area is highly dissected and rough, with high north-east relief which made it susceptible for such earthquake induced landslides which therefore necessitates the need of a detailed study. It is important to identify the landslide prone area to conduct quicker and safe mitigation program to ensure replication of such study in other landslide prone areas as well. The statistical approach 

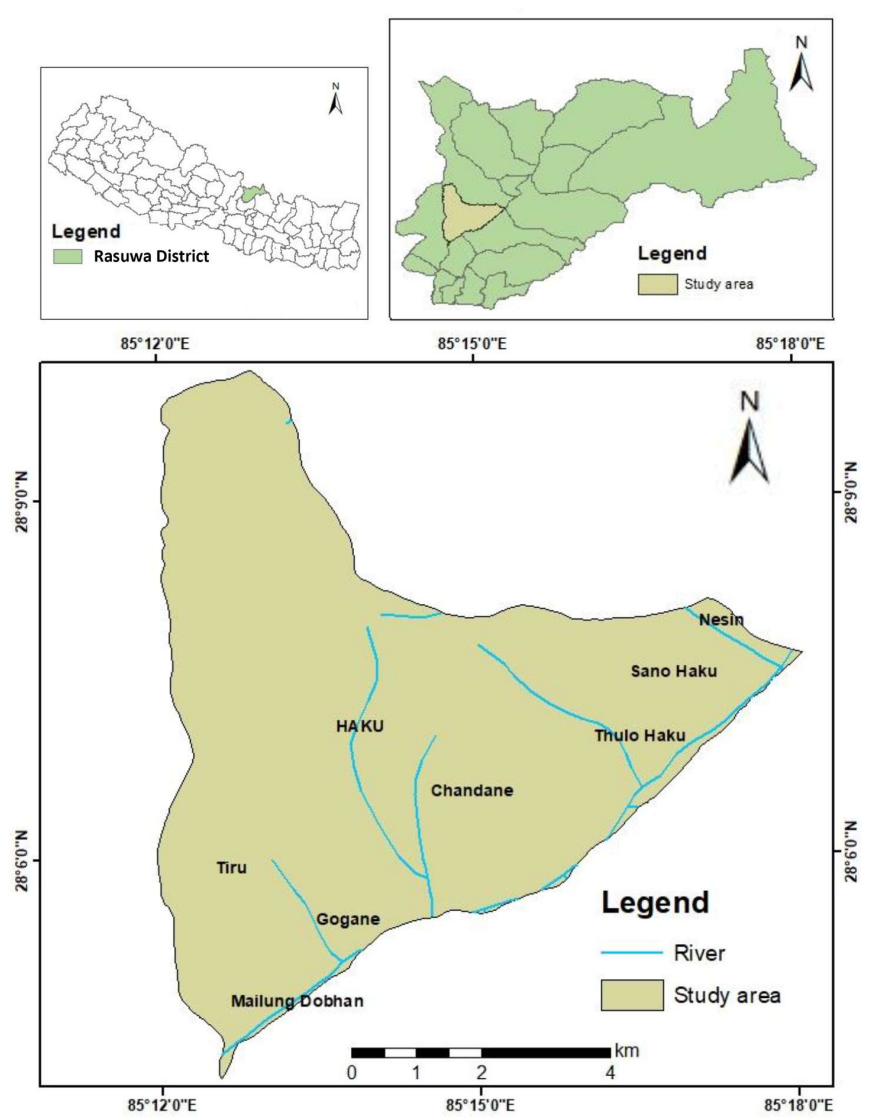

Fig. 1: Location map of study area

usually incorporates factors namely slope, elevation, drainage proximity etc. with peak ground acceleration (PGA) as the triggering factor (Miles and Keefer 2007; 2009a; 2009b). Landslide susceptibility mapping approaches for earthquake induced landslides vary from heuristic (Knowledge based) approach to data driven approach (Statistical approach). This study uses bivariate statistical method, Weight of Evidence method for preparing the susceptibility map. Bivariate statistical method can be a very approach to derive which factors are responsible for the occurrence of landslide event in an area. In some cases, the performance simulated and success rate of weight of evidence is very high compared to other approaches (Pradhan and Lee, 2010).

\section{STUDY AREA}

The Haku area lies towards the southern part of the Rasuwa District, Nepal (Fig. 1). The topography of the area is highly dissected and rough which makes it susceptible to landslides. According to the statistics to MoHA around 400 families were displaced after the 2015 Gorkha earthquake. The altitude of the area ranges from $740 \mathrm{~m}$ to as high as $4032 \mathrm{~m}$ and the total area under study is $49.82 \mathrm{sq}$. $\mathrm{km}$. The study area is bounded by $28^{\circ} 10^{\prime} 0^{\prime \prime} \mathrm{N}$ to $28^{\circ} 4^{\prime} 00^{\prime \prime} \mathrm{N}$ latitude and $85^{\circ} 12^{\prime} 0^{\prime \prime}$ E to $85^{\circ} 18^{\prime} 00^{\prime \prime}$ E longitude. The study area can be accessed by the Pasang Lhamu Highway. It is also linked with many graveled road and foot trails.

Climate in Haku area can vary from sub-tropical to full glacial, rainy season characterized by high and intensive rainfall from June to September caused by the monsoon from the southwest, with precipitations around 1,990 $\mathrm{mm}$ per year (Acharya et al., 2006; Sill and Kirby, 2013). The study area is full of diverse vegetation as there is variation in altitude.

Due to steep slope, rugged topography and the fragile rock condition, the Haku area is susceptible to many slope instability issues.

\section{METHODOLOGY OF STUDY}

The landslide inventory of the study area was developed by the aid of Google Earth. The Post-Earthquake and PreEarthquake images were analyzed with the help of Google Earth historical archive tool (Fig. 2 (a)). Field verification was conducted to check on randomly selected landslide polygons in the study area. Several past landslides were reactivated after the 2015 Gorkha Earthquake (Fig. 2 (b)).
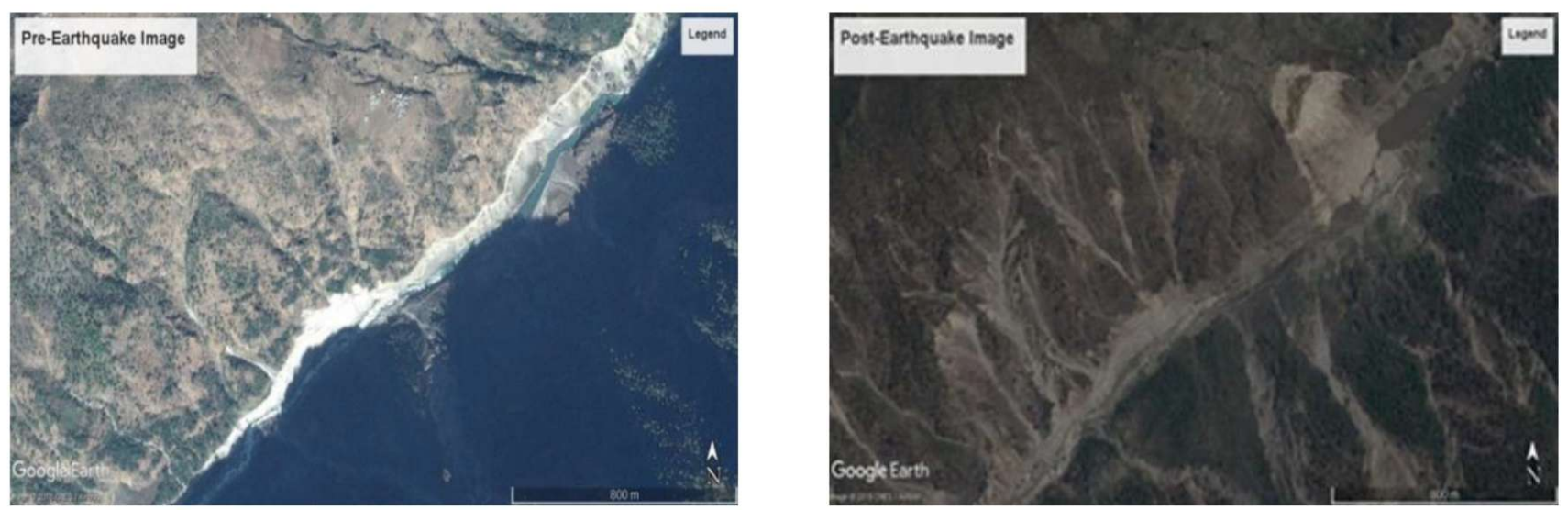

Fig. 2: Google earth image of the study area (a) Pre-Earthquake image (b) Post Earthquake image near Tiru village, Rasuwa 


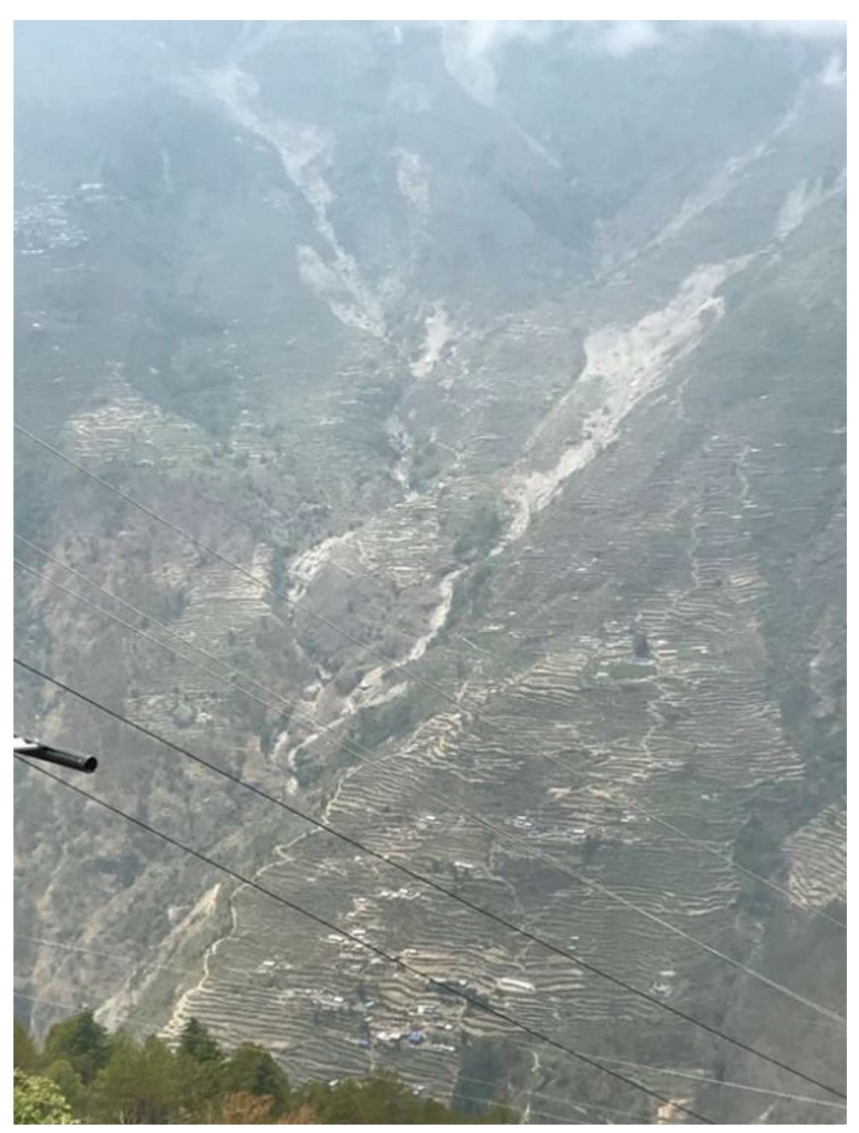

Fig. 3: Landslide representing Thulo Haku and Sano Haku, Rasuwa

Altogether 101 earthquake induced landslides were identified by studying Google image preparing landslide inventory by comparison of Pre-earthquake (23rd April, 2015) and Post-earthquake image (4th May, 2015) (Fig. 4).

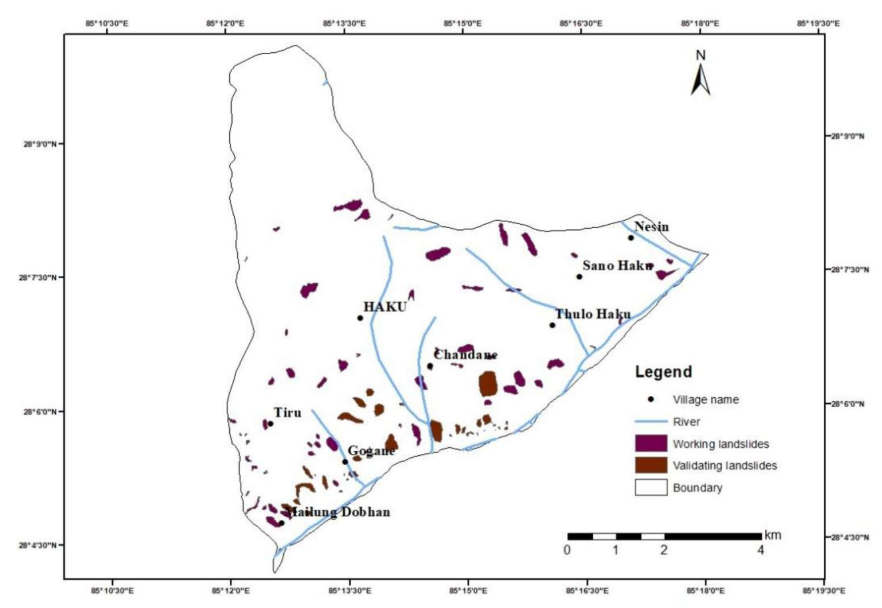

Fig. 4: Landslide inventory of study area

\section{Landslide influencing factors}

The selection of factors contributing landslides is a very complex phenomenon. The contributing factors were identified and selected in this study based on the presence or absence of the factors and their importance. The landslide conditioning factors incorporated the geological, geomorphological, anthropogenic and extrinsic factors. In this study, 8 conditioning factors were considered to prepare the landslide susceptibility map namely, peak ground acceleration (PGA), slope aspect, slope, landuse, geology, elevation and curvature.

\section{$P G A$}

Peak Ground Acceleration (PGA) is an extrinsic parameter considered in this study. Peak ground acceleration (PGA) is equal to the maximum ground acceleration that occurred during earthquake shaking at a location. PGA is equal to the amplitude of the largest absolute acceleration recorded on an accelerogram at a site during a particular earthquake. Earthquake shaking generally occurs in all three directions. Therefore, PGA is often split into the horizontal and vertical components. Horizontal PGAs are generally larger than those in the vertical direction but this is not always true, especially close to large earthquakes. PGA is linked with the seismic intensity produced due to the earthquakes. Generally, the number of earthquake induced landslides has a proportional relationship with the PGA value. This means the number of earthquake induced landslides abruptly increases with the rise in the PGA values (Liao and Lee 2000). The PGA attribute of the study area was extracted from the PGA map related to the Gorkha earthquake (USGS 2015), which was released by the US Geological Survey (USGS, ). From the spatial distribution analysis of the landslide, it shows a very good correlation with PGA. It can be seen that the landslide was mainly distributed, where the PGA is high. In comparison with the felt earthquake intensity, 0.6 and a higher PGA indicate violent to extreme shaking. This can thus generate a large number of co-seismic landslides in steep mountain slopes (Regmi et al., 2016) The PGA data was obtained from the United States Geological Survey (USGS) by the use of the PGA map prepared after the Gorkha earthquake. The PGA map of the Haku area is shown in Fig. 6 (a). From the analysis of the distribution of the earthquake induced landslides we find a positive correlation between the number of landslides and PGA values (Shrestha et al., 2018). The study shows that the landslide distribution is maximum for area with higher PGA.

\section{Topographic Parameters}

Digital elevation model (DEM) has been used as an important factor in the study of earthquake induced landslides (Kamp et al., 2008; Wang et al., 2015). A DEM of cell size 30* 30 prepared from the digital contour obtained from Department of Survey, Nepal was used to extract the topographic factors like slope, aspect, curvature (plan and profile). Research shows an increase in the probability of landslide occurrence for higher elevation although there is absence of any direct relationship 


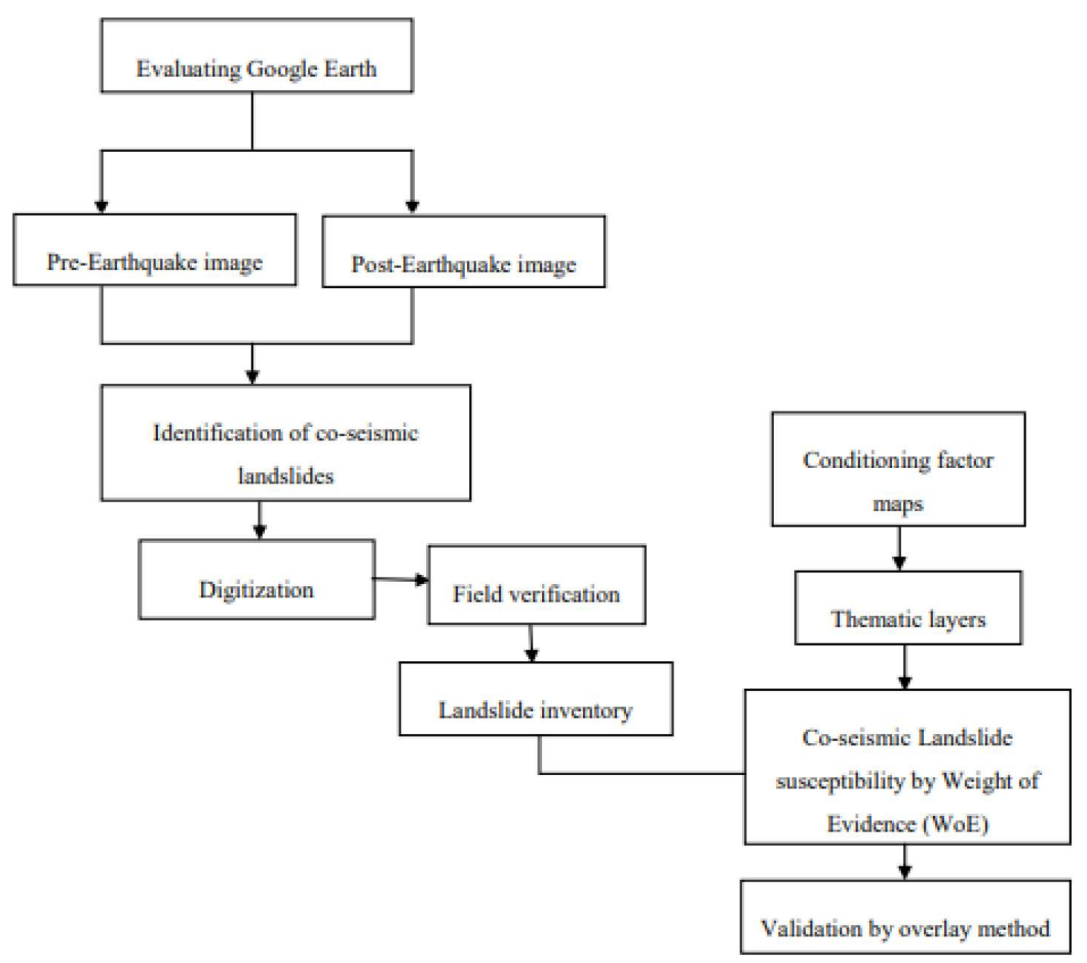

Fig. 5: A simplified flowchart showing methodology of study

between the elevation and landslide occurrence (Ercanoglu et al., 2004). The elevation ranges in the study area from 500-4500 $\mathrm{m}$ as represented in Fig. 6 (b). The landslide concentration was maximum for elevation range 1500-2500 m. The steepness of the slope is another major topographic factor used in landslide susceptibility studies (Wang et al. 2015; Kamp et al., 2008; Regmi et al., 2016; Regmi et al., 2010; Pradhan and Lee, 2010). The slope ranges from $0^{\circ}-70^{\circ}$ as shown in Fig. 6 (c). The landslide concentration was maximum along the slope range from $35^{\circ}-45^{\circ}$ because the soil deposits are resting on these slopes and they became unstable during the earthquake shocks. The aspect of the slope resembles the moisture retention and it's relation to attitude of bedding of the rock formation which in turn affects the physical properties of slope material and it's susceptibility to failure (Dai et al., 2001). In this study, aspect to the south and south east contributes mostly to landslides (Fig. $6(d))$. It is usually because most of the river segment trend towards E-W and many landslides appear on the slope towards the river.

The shape of the slope can play major role in triggering landslide as it has a strong influence on creating slope instability. In curvatures, the landslides are usually distributed in convex slopes (Figs. 6(e) and 6(f)). The convex slopes usually have earthquake induced landslides (Reneau and Dietrich, 1987).

\section{Geological Factor}

The digital Geological map prepared by the Department of Mines and Geology, Government of Nepal was used during the study. The study area lies at a close distance from the Main Central Thrust (MCT). The MCT crops out on both sides of the Trishuli Valley. The study area consists of the Ulleri Formation which comprises of the Augen gneiss, muscovite biotite, gneisses feldspathic schists and the Seti Formation which comprises of grey, greenish grey gritty phyllites, gritstones with conglomerate and white massive quartzite, with basic intrusions noted in the upper parts (Fig. 6(g)). From the correlation of the geological factor with landslide distribution it was noted that maximum landslides occurred in the Seti Formation. This formation consists of highly fractured and jointed rocks that were severely affected by the earthquake.

\section{Anthropogenic Factor}

Landuse is considered to be one of the landslide conditioning factors as the variation in the landuse might play a role in changing the vegetation cover varying the mechanical (e.g. soil strength and slope behavior) and hydrological (e.g. Greenway, 1987; van Westen et al., 2003; Reichenbach et al., 2014). The variation in land use distribution may be either natural, human induced or a combination of both. Landuse map was generated by digitizing the attributes in Google Earth Image and exporting them to GIS for final extraction of the landuse of the study area of cell size 30x30 m (Fig. 6(h)).The weight values depict that the correlation of grassland and barren land that is 2.004 and 0.404898 respectively is stronger than other land use classes and our results contrast in the respect that we have obtained maximum landslide area in forest class. This 
might be because the forest covers the maximum area from the total study area.

A brief summary of the methodology employed during the study is given in Fig. 5 .

\section{WEIGHT OF EVIDENCE METHOD}

In the study area, Weight of Evidence Method, a bivariate statistical approach was employed to make the susceptibility map of earthquake induced landslides.

The Weight-of-Evidence (WoE) method is a statistical tool that uses the prior probability of occurrence of an event to find out its posterior probability based on relative role of landslide-controlling parameters (van Westen, 2002). This method utilizes the historical data events to obtain the conditioning parameters for the occurrence of landslide (Sumatra et al., 2014).

Prior and posterior probabilities of a landslide occurrence (L), given the presence or absence of any parameter class in binary pattern ( $\mathrm{Mi}$ or $\mathrm{Mi}$ ) are calculated using the following equations: area]

Prior probability $=\mathrm{P}(\mathrm{L})=[$ Total Landslides $/$ Total study

Posterior probability $=\mathrm{P}(\mathrm{L} / \mathrm{M})=(\mathrm{P}(\mathrm{L} \cap \mathrm{Mi})) /(\mathrm{P}(\mathrm{Mi}))$

In the raster form, all the data are in pixel form. So, the above equation can be rewritten as:

$$
\begin{aligned}
& \mathrm{P}(\mathrm{L})=(\text { Npix }(\text { Landslide })) /(\text { Npix }(\text { Total })) ; \text { and } \\
& \mathrm{P}(\mathrm{L} / \mathrm{M})=(\operatorname{Npix}(\mathrm{L} \cap \mathrm{Mi})) /(\operatorname{Npix}(\mathrm{Mi}))
\end{aligned}
$$

Where, Npix (L) and Npix (Total) are the number of pixels that existing landslides belong, and number of pixels covering total area, respectively.

For the calculation of weights, Positive $(\mathrm{W}+)$ and negative (W-) weights are developed using conditional probabilities as following.

$$
\begin{aligned}
& \mathrm{W}+=\operatorname{loge}[(\mathrm{P}(\mathrm{Mi} \mid \mathrm{L})) /(\mathrm{P}(\mathrm{Mi} / \mathrm{L}))] \\
& \mathrm{W}-=\operatorname{loge}[(\mathrm{P}((\mathrm{Mi} \mid \mathrm{L})) /(\mathrm{P}(\mathrm{M} \mathrm{i} / \mathrm{L}))]
\end{aligned}
$$

where, $\mathrm{W}+$ indicates the importance of the presence of a parameter class/ conditioning factor for the occurrence of landslides. W-indicates the importance of the absence of a parameter class for the occurrence of landslides.

A total weight of each multiclass factor map was estimated by adding the positive weight of a class to the total negative weight of the same factor map as:

$$
\mathrm{Wmap}=\mathrm{Wplus}+\mathrm{Wmin}(\text { total })-\mathrm{Wmin}
$$

where

Wmin $($ total $)=$ the total of all negative weights in a multiclass map
The weights are finally used to derive the contrast value (C) given by:

$$
\mathrm{C}=\mathrm{W}+-\mathrm{W}-
$$

\section{RESULTS AND DISCUSSION}

The study represented that maximum number of landslides occurred along the Trishuli Ganga river section. Most of the landslides in study area were further increasing the vulnerability of the slope. From the field observation it was noted that toe cutting by river was also one of the prime factors triggering the landslide. The major effect of the landslide in the Haku area however was posing serious issue to the settlement. The weight values were calculated individually for the eight conditioning factors to produce estimated evidence. The results of the weight value calculation are given in Table 1 . Higher the values of $\mathrm{W}+$ stronger get the positive correlation (Sumatra et al., 2014) which is validated by our study for different factors as well high positive correlation to the landslides are observed for the angle greater than $45^{\circ}$ and then in the angle ranges within $35^{\circ}-45^{\circ}$. For aspect class, landslides are more correlated on slopes facing south and south east. The elevation range 1500-2500 meters alone shows a positive correlation as observed from Table 1 which is nearly1.Similarly, for the plan curvature, maximum correlation was obtained for concave slopes which clarifies that landslides are more prone to concavity of the slopes. The correlation of landslides to concave surface in plan curvature is 0.122775 as obtained from Table 1 . The geological class, the Seti Formation shows maximum correlation compared to Ulleri which is 1.945618 . The correlation value is nearly 2 , which represents that the correlation is significant enough. The weight values for landuse class grassland and barren land that is 2.004 and 0.404898 respectively is greater than other land use classes and our results contrast in the respect that we have obtained maximum landslide area in forest class. This might be because the forest covers the maximum area from the total area. The PGA value of range $0.56-0.68$ shows positive correlation with the occurrence of landslide which is 1.012 as observed from Table 1. Also, this study shows that maximum landslides were reported in this PGA class which validates the similar results obtained from the model. Therefore, the statistical analysis obtained from the results of the susceptibility map prepared by using WoE model gave the results that maximum area of landslide distribution was observed in medium and high susceptibility class i.e. $38 \%$ and $33 \%$ followed by very high (13\%), low (10\%) and very low classes $(5.8 \%)$.

\section{VALIDATION OF MODEL}

The susceptibility map prepared is given in Fig. 7. For the validation of the landslide susceptibility map, first the total number of landslides was divided into two parts. First $75 \%$ of landslides were tested for the models and remaining $25 \%$ of landslides were used for the validation of the models. The numbers of landslides were selected as per the representation for all the contributing factors used in the study and the validation 


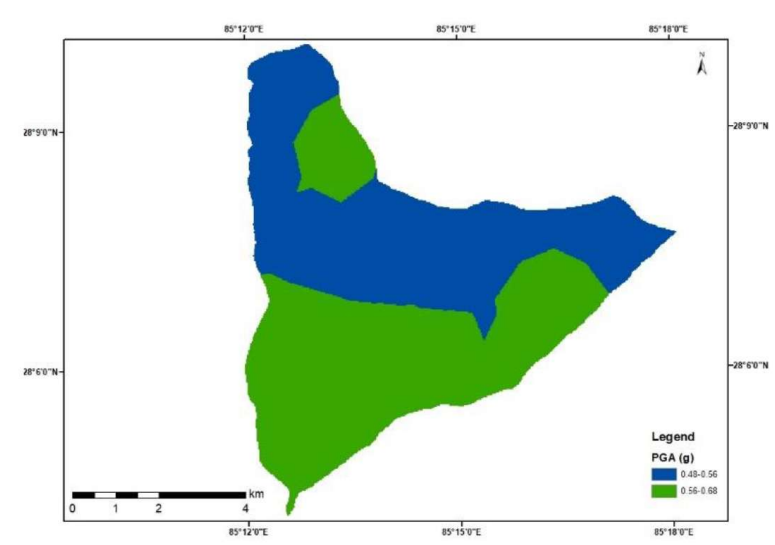

(a)

(c)

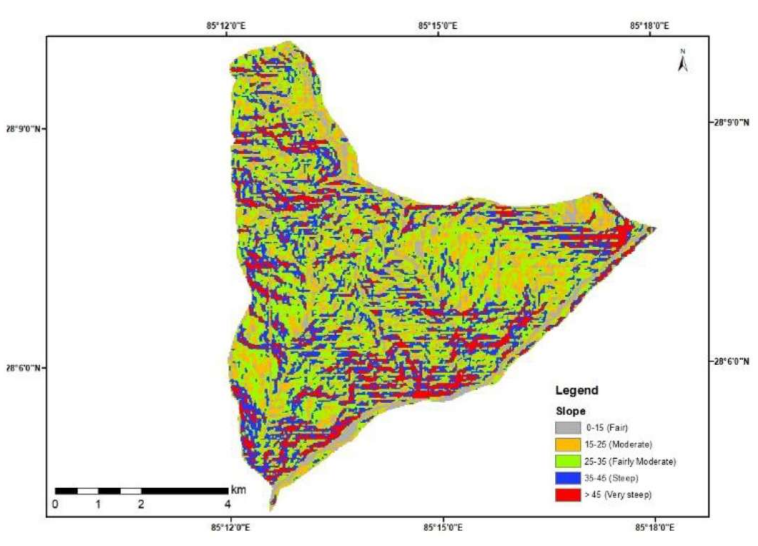

(e)
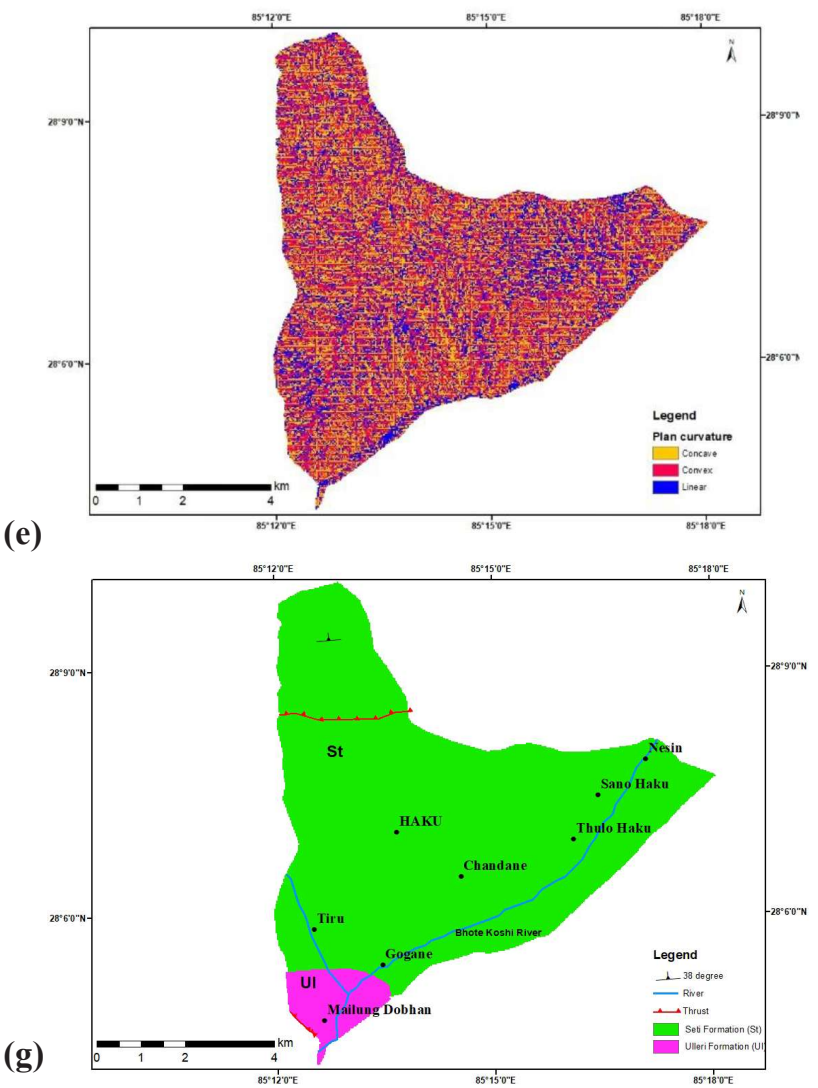

(b)

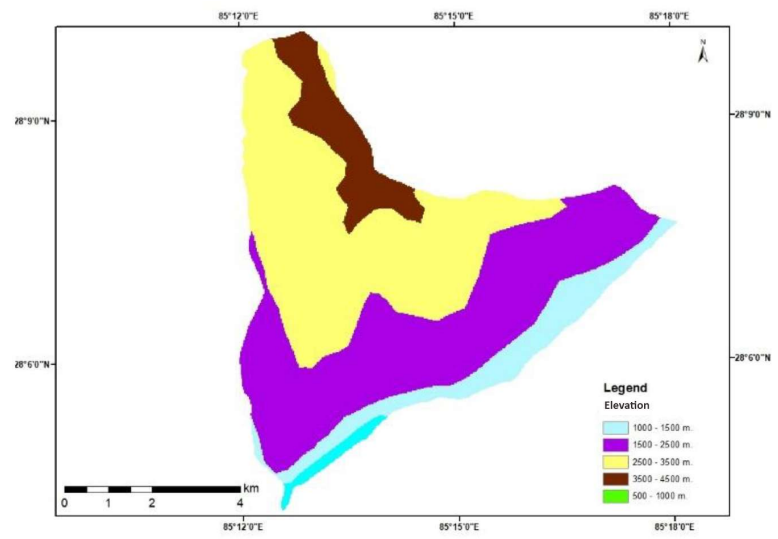

(d)

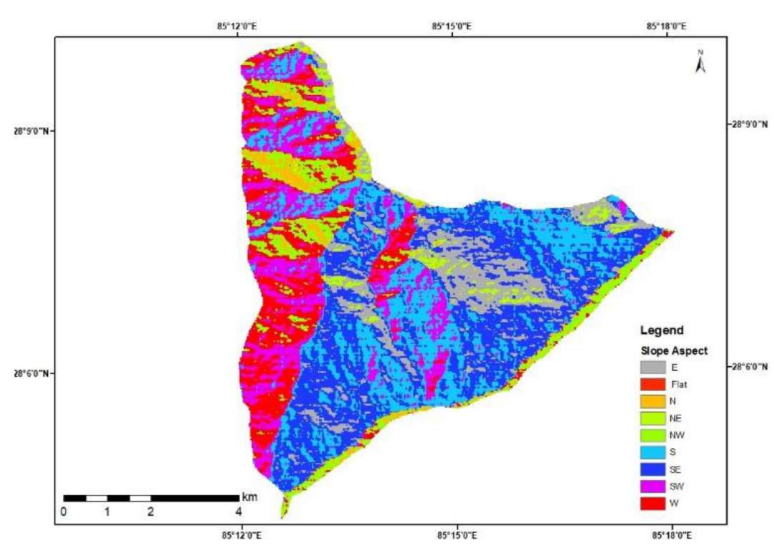

(f)

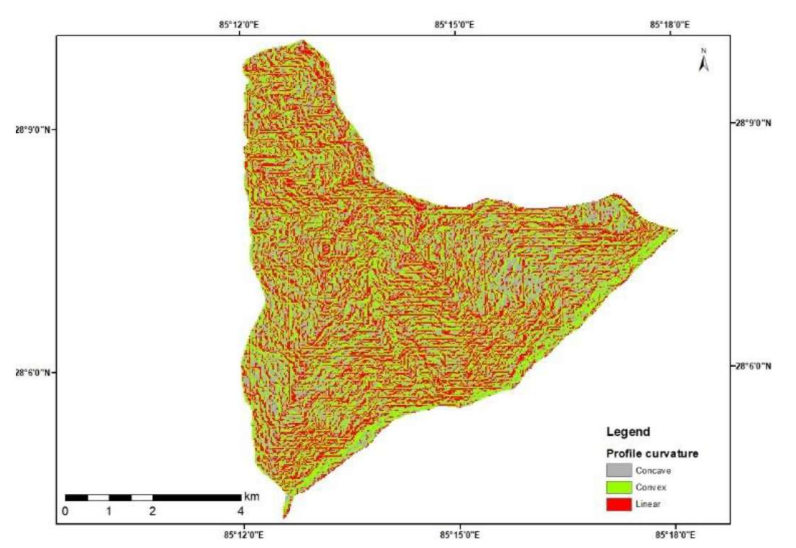

(h)

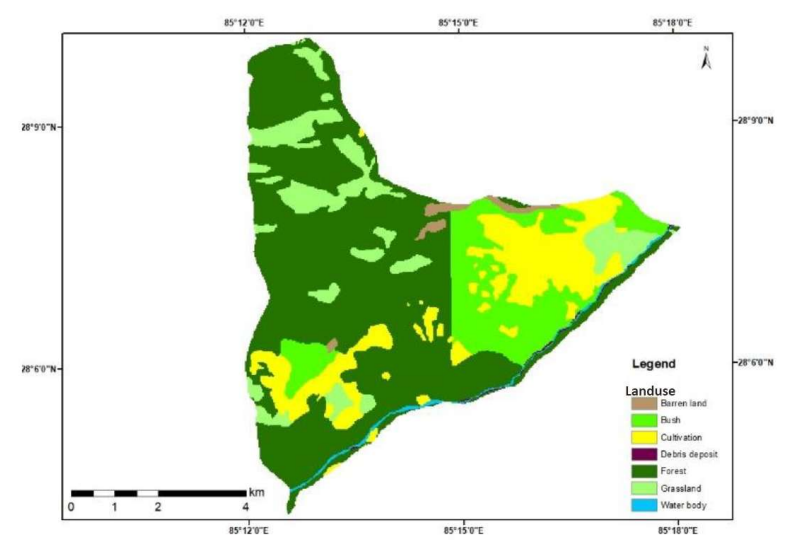

Fig. 6: (a) PGA map of study area (1g=981 gals), (b) Elevation map of study area, (c) Slope map of study area (d) Slope Aspect map of study area, (e) Plan curvature map of study area, (f) Profile curvature map of study area, (g) Geological map of study area, and (h) Landsue map of study area 
Table 1: Weight values of respective contributing factors

\begin{tabular}{|c|c|c|c|c|c|c|c|c|c|}
\hline S.N. & Class & $\begin{array}{l}\text { Pixel } \\
\text { count of } \\
\text { total area } \\
\text { in a class }\end{array}$ & $\begin{array}{l}\text { Pixel } \\
\text { count of } \\
\text { landslide } \\
\text { area in a } \\
\text { class }\end{array}$ & $\begin{array}{l}\text { Pixel count } \\
\text { of landslide } \\
\text { area outside } \\
\text { the class }\end{array}$ & $\begin{array}{l}\text { Pixel } \\
\text { count of } \\
\text { stable area } \\
\text { in a class }\end{array}$ & $\begin{array}{l}\text { Pixel count } \\
\text { of stable } \\
\text { area outside } \\
\text { the class }\end{array}$ & Wplus & Wminus & Weight \\
\hline \multirow[t]{7}{*}{1} & \multicolumn{9}{|c|}{ Slope (degree) } \\
\hline & $0-15$ & 5152 & 76 & 2636 & 5076 & 63175 & -0.97604 & 0.04886 & -1.0249 \\
\hline & $15-25$ & 16006 & 307 & 2405 & 15699 & 52552 & -0.709 & 0.141252 & -0.85025 \\
\hline & $25-35$ & 24278 & 609 & 2103 & 23669 & 44582 & -0.4346 & 0.17154 & -0.60614 \\
\hline & $35-45$ & 17782 & 937 & 1775 & 16845 & 51406 & 0.33638 & -0.14045 & 0.476829 \\
\hline & $>45$ & 7745 & 783 & 1929 & 6962 & 61289 & 1.040416 & -0.23309 & 1.273509 \\
\hline & Total & 70963 & 2712 & & 68251 & 61289 & & & \\
\hline \multirow[t]{12}{*}{2} & \multicolumn{9}{|l|}{ Aspect } \\
\hline & Flat & 2 & 1 & 2711 & 1 & 68249 & -0.63273 & 0.086534 & -0.71926 \\
\hline & $\mathrm{N}$ & 611 & 1 & 2711 & 610 & 67640 & -0.60258 & 0.042654 & -0.64523 \\
\hline & $\mathrm{NE}$ & 1910 & 6 & 2706 & 1904 & 66346 & -0.70258 & 0.04678 & -0.74936 \\
\hline & E & 8394 & 180 & 2532 & 8214 & 60036 & -0.30215 & 0.036542 & -0.33869 \\
\hline & SE & 18541 & 1017 & 1695 & 17524 & 50726 & 1.378391 & -0.17327 & 1.551661 \\
\hline & SE & 15082 & 1061 & 1651 & 14021 & 54229 & 1.28973 & -0.26635 & 1.556077 \\
\hline & SW & 10095 & 337 & 2375 & 9758 & 58492 & -0.13719 & 0.021158 & -0.15835 \\
\hline & W & 9623 & 105 & 2607 & 9518 & 58732 & -1.28147 & 0.110704 & -1.39218 \\
\hline & NW & 5473 & 4 & 2708 & 5469 & 62781 & -1.06543 & 0.082048 & -1.14748 \\
\hline & \multirow[t]{2}{*}{$\mathrm{N}$} & 1232 & 1 & 2711 & 1231 & 67019 & 0 & 0.018216 & -0.01822 \\
\hline & & 70963 & 2712 & & 68250 & & & & \\
\hline \multirow[t]{7}{*}{3} & \multicolumn{9}{|c|}{ Elevation (in m.) } \\
\hline & $2500-3500$ & 29335 & 646 & 2066 & 28689 & 39687 & -0.56613 & 0.271926 & -0.83806 \\
\hline & $1500-2500$ & 27251 & 1647 & 1065 & 25604 & 42772 & 0.483542 & -0.46557 & 0.949116 \\
\hline & $500-1000$ & 991 & 5 & 2707 & 986 & 67390 & -2.05688 & 0.01268 & -2.06956 \\
\hline & $3500-4500$ & 6475 & 152 & 2560 & 6323 & 62053 & -0.50073 & 0.039354 & -0.54009 \\
\hline & $1000-1500$ & 7036 & 262 & 2450 & 6774 & 61602 & -0.02517 & 0.002729 & -0.0279 \\
\hline & & 71088 & 2712 & & 68376 & & & & \\
\hline \multirow[t]{5}{*}{4} & \multicolumn{9}{|c|}{ Plan Curvature } \\
\hline & Concave & 25516 & 1050 & 1662 & 24466 & 43785 & 0.077011 & -0.04576 & 0.122775 \\
\hline & Linear & 17745 & 553 & 2159 & 17192 & 51059 & -0.21134 & 0.062169 & -0.2735 \\
\hline & Convex & 27702 & 1109 & 1603 & 26593 & 41658 & 0.048316 & -0.03211 & 0.080427 \\
\hline & & 70963 & 2712 & & 68251 & & & & \\
\hline \multirow[t]{5}{*}{5} & \multicolumn{9}{|c|}{ Profile Curvature } \\
\hline & Convex & 30278 & 1212 & 1500 & 29066 & 39185 & 0.048208 & -0.03732 & 0.085532 \\
\hline & Linear & 23247 & 1037 & 1675 & 22210 & 46041 & 0.161295 & -0.08821 & 0.249508 \\
\hline & Concave & 17438 & 463 & 2249 & 16975 & 51276 & -0.37626 & 0.098769 & -0.47503 \\
\hline & & 70963 & 2712 & & 68251 & & & & \\
\hline \multirow[t]{9}{*}{6} & \multicolumn{9}{|l|}{ Landuse } \\
\hline & Forest & 39681 & 1304 & 1408 & 38377 & 29987 & 0.06321 & -0.42318 & 0.48639 \\
\hline & Barren land & 7945 & 424 & 2288 & 7521 & 60843 & 0.351439 & -0.05346 & 0.404898 \\
\hline & Water body & 11214 & 122 & 2590 & 11092 & 57272 & -1.2828 & 0.131006 & -1.4138 \\
\hline & Grassland & 872 & 189 & 2523 & 683 & 67681 & 1.942412 & -0.0622 & 2.004609 \\
\hline & $\begin{array}{l}\text { Cultivated } \\
\text { land }\end{array}$ & 10566 & 661 & 2051 & 9905 & 58459 & 0.520119 & -0.12284 & 0.642957 \\
\hline & Bush & 641 & 10 & 2702 & 631 & 67733 & -0.91756 & 0.005579 & -0.92314 \\
\hline & $\begin{array}{l}\text { Debris } \\
\text { deposit }\end{array}$ & 157 & 2 & 2710 & 155 & 68209 & -1.12312 & 0.001532 & -1.12465 \\
\hline & Total & 71076 & 2712 & & 68364 & & & & \\
\hline \multirow[t]{4}{*}{7} & Geology & & & & & & & & \\
\hline & Ulleri & 4088 & 351 & 2361 & 3737 & 64711 & 1.86316 & -0.08246 & 1.945618 \\
\hline & Seti & 67072 & 2361 & 351 & 64711 & 3737 & -0.3426 & 0.863136 & -1.20574 \\
\hline & Total & 71160 & 2712 & & 68448 & & & & \\
\hline \multirow[t]{4}{*}{8} & \multicolumn{9}{|l|}{ PGA (gals) } \\
\hline & $0.56-0.68$ & 37337 & 2024 & 688 & 35313 & 33051 & 0.367985 & -0.64486 & 1.012843 \\
\hline & $0.48-0.56$ & 33739 & 688 & 2024 & 33051 & 35313 & -0.64486 & 0.367985 & -1.01284 \\
\hline & Total & 71076 & 2712 & & 68364 & & & & \\
\hline
\end{tabular}




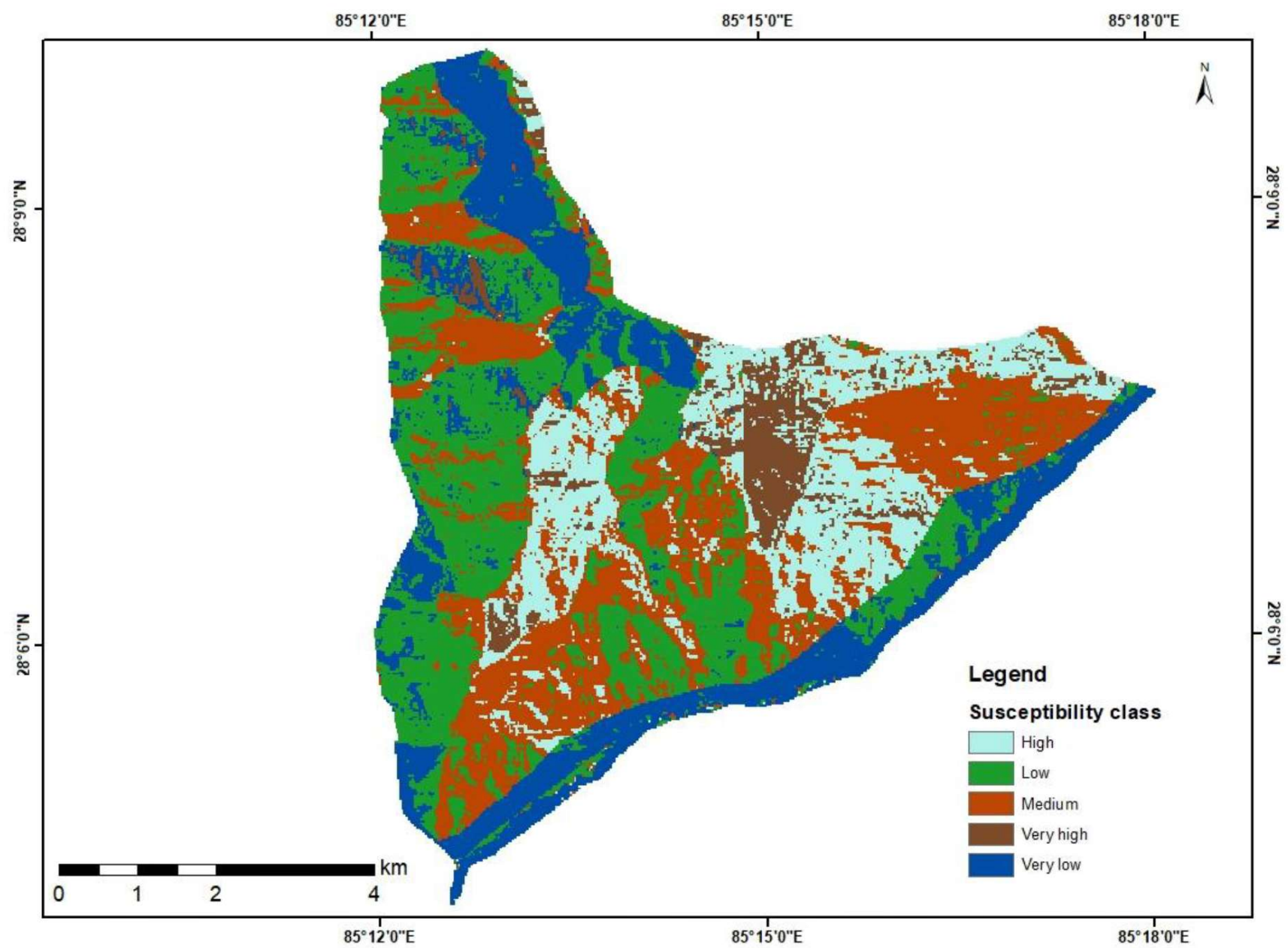

Fig. 7: Susceptibility map of study area

was conducted along with field study. For the validation, overlay method was used. Validation of landslides further shows that the WoE method is significant as most of the landslide area lies in moderate, high and very high susceptibility class (Figure 8). The probability value however estimated in these kinds of predictive models are not always absolute and represent relative degree of susceptibility only (Dahal et al., 2008). Though, such predictive values can be an initiation for measure of study of the landslide susceptibility in the study area.

\section{CONCLUSION}

In this study, Weight of Evidence model based on bivariate statistical method was used for determining the spatial probability of landslide occurrence where each factor layer was weighted according to the contribution on landslides. This method predicted the probability of landslide occurrence efficiently which was validated by positive correlations between the field conditions and the results obtained by the model. A total of 101 landslides were identified in this study from the preparation of factor maps, it is found that landslides are more influenced by higher slopes or increasing relief. It was observed that the slope angle less than 15 degrees didn't induce landslide. The results suggested that the landslides are mostly common in slope facing towards south and south east. While the curvature suggested that concave curvature is the role player to predict landslides. For the study of elevation suggested the increase in number of landslide till $2500 \mathrm{~m}$ and then a sudden decline in area percentage of landslide. The Seti Formation comprising of gritty phyllite, quartzite and conglomerate suggested maximum landslide distribution due

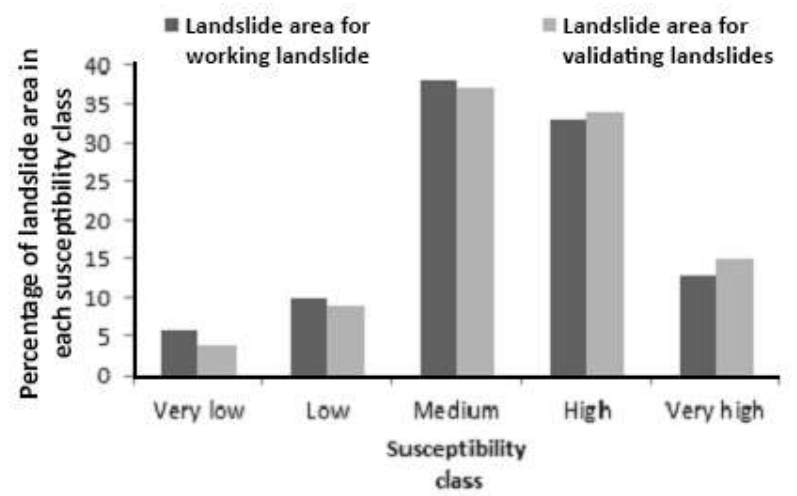

Fig. 8: Bar-graph showing validation of the model 
to the fragile weathered rock. The forest area followed by barren land covered maximum area in the Haku region as obtained from the results. It was found from the study that the PGA value had a direct correlation with the landslide event as the landslide distribution increased with the PGA value. PGA is a conditioning factor and is associated with seismic intensity. In general, coseismic landslides increase with PGA values (Liao and Lee 2000). The statistical analysis obtained from the results of the susceptibility map prepared by using WoE model gave the results that maximum area of landslide distribution was observed in medium and high susceptibility class i.e. $38 \%$ and $33 \%$ followed by very high (13\%), low (10\%) and very low classes $(5.8 \%)$. Similarly, the validating landslides showed similar results as obtained from the model. Among the different factors determined, slope, aspect, and geology were found to be the major contributors to trigger the earthquake induced landslides in the Haku area.

\section{REFERENCES}

AAcharya, G., De Smedt, F., and Long, N.T., 2006, Assessing landslide hazard in GIS: A case study from Rasuwa, Nepal. Bull. Eng. Geo. and Envir., v. 65(1), pp. 99-107. https://doi.org/10.1007/s 10064-005-0025-y

Amatya, S.C., 2106, Landslide Disaster Management in Nepal, A near-future perspective (Report). Nepal-Japan Friendship Association of water Induced Disaster (NFAD), Japan and Department of Water Induced Disaster Management (DWIDM).

Dahal, R.K., Hasegawa, S., Nonomura, A., and Yamanaka, M., 2008, Regional Scale Landslide Susceptibility Mapping in the Lesser Himalayan Terrain of Nepal, pp. 1-12.

Dai, F.C., Lee, C.F., Li.J., Xu, Z.W., 2001, Assessment of landslide susceptibility on the natural terrain of LantauIsland, Hongkong, Environ Geol, v.40(3), pp. 381-391. https://doi.org/10.1007/s002540000163

Dewey, J.F., and Burke, K.C., 1973, Tibetan, Variscan, and Precambrian basement reactivation: 2 products of continental collision; J. Geol. v.81(6), pp. 683-692. https://doi.org/10.1086/627920

Ercanoglu, M., Gokceoglu, C., and Van Asch, T.W., 2004, Landslide susceptibility zoning north of Yenice (NW Turkey) by multivariate statistical techniques; Nat. Hazards, v.32(1), pp. 1-23.

https://doi.org/10.1023/B:NHAZ.0000026786.85589.4a

Greenway, D.R., 1987, Vegetation and slope stability. In: Anderson M.G., Richards, K.S (eds) slope stability, pp. $187-230$.

Kamp, U., Growley, B.J., Khattak, G.A., and Owen, L.A., 2008, GIS-based landslide susceptibility mapping for the 2005 Kashmir earthquake region; Geomorphology, v.101(4), pp. 631-642. https://doi.org/10.1016/j.geomorph.2008.03.003

Keefer, D.K., 1994. The importance of earthquake-induced landslides to long-term slope erosion and slope-failure hazards in seismically active regions; Geomorphology, pp. 265-284. https://doi.org/10.1016/B978-0-444-820129.50022-0

Liao, H.W., and Lee, C.T., 2000, Landslides triggered by the Chi-Chi earthquake; In Proceedings of the 21st Asian conference on remote sensing, Taipei, pp. 1-2.

Miles, S.B., and Keefer, D.K., 2007, Comprehensive areal model of earthquake-induced landslides: technical specification and user guide; US Geol. Survey.

https://doi.org/10.3133/ofr20071072

Miles, S.B., and Keefer, D.K., 2009a, Evaluation of CAMELcomprehensive areal model of Earthquake-induced landslides; Eng. Geol, v.104(1), pp. 1-15.

https://doi.org/10.1016/j.enggeo.2008.08.004

Miles, S.B., and Keefer, D.K., 2009b, Toward a comprehensive areal model of earthquake-induced landslides; Nat hazards review, v. 10(1), pp. 19-28.

https://doi.org/10.1061/(A S E ) 1527 6988(2009)10:1(19)

Ministry of Home Affairs (MoHA), 2015, Nepal Disaster Report 2015.

Pradhan, B., and Lee, S., 2010, Landslide susceptibility assessment and factor effect analysis: back propagation artificial neural networks and their comparison with frequency ratio and bivariate logistic regression modeling; Environ. Modell. Softw., v.25, pp. 747-759.

https://doi.org/10.1016/j.envsoft.2009.10.016

Regmi, A.D., Dhital, M.R., Zhang, J.Q., Su, L.J., and Chen, X.Q., 2016, Landslide susceptibility assessment of the region affected by the 25 April 2015 Gorkha earthquake of Nepal; J. Mt. Sci. v.13(11), pp. 1941-1957.

https://doi.org/10.1007/s 11629-015-3688-2

Regmi, N.R., Giardino, J.R., and Vitek, J.D., 2010, Modeling susceptibility to landslides using the weight of evidence approach: Western Colorado, USA; Geomorphology, v. 115 , pp. $172-187$.

https://doi.org/10.1016/j.geomorph.2009.10.002

Reichenbach, P., Busca, C., Mondini, A.C., and Rossi, M., 2014, The influence of land use change on Landslide Susceptibility Zonation: The Briga Catchment Test Site, v. 54(6), pp. 1372-1384.

https://doi.org/10.1007/s00267-014-0357-0

Reneau, S.L., and Dietrich, W.E., 1987, Size and location of colluvial landslides in a steep forested landscape; IAHSAISH publication, v.165, pp. $39-48$. 
https://doi.org/10.1130/REG7-p165

Shrestha, S., and Kang, Tae-Seob and Chan Choi, J., 2018, Assessment of Co-Seismic Landslide Susceptibility Using LR and ANCOVA in Barpak Region, Nepal. Journal of Earth System Science. pp-127.

https://doi.org/10.1007/s 12040-018-0936-1

Sill, M., and Kirkby, J., 2013, Atlas of Nepal in the Modern World. London: Taylor and Francis.

https://doi.org/10.4324/9781315066066

Sumatra, W., Muslim, D., Sulaksana, N., and Dasatriana, Y., 2014, Weights of Evidence Method for Susceptibility Mapping in Tandikek and Damar, v.10, pp. 1283-1290.

United States Geological Survey (USGS), 2015, M7.8-34 km
ESE of Lamjung, Nepal Earthquake (last accessed 19.05.2015, map version 7).

Van Westen, C.J., Rengers, N., Soeters, R., 2003, Use of geomorphological information in indirect landslide susceptibility assessment. Nat Hazards, v. 30, pp. 399-411.

https://doi.org/10.1023/B:NHAZ.0000007097.42735.9e

Van Westen, C.J., 2002, The modeling of landslide hazards using GIS. Survey in Geophysics, v. 2, pp. 241-255.

Wang, L.J., Guo, M., Sawada, K., Lin, J., and Zhang, J., 2015,Landslide susceptibility mapping in Mizunami City, Japan: A comparison between logistic regression, bivariate statistical analysis and multivariate adaptive regression spline models; Catena, v.135, pp. 271-282.

https://doi.org/10.1016/j.catena.2015.08.007 